\title{
Posttranslational regulation of the bile salt export pump
}

\author{
Susanne Przybylla, Lutz Schmitt ${ }^{*}$ \\ From 1st International Conference of Collaborative Research Center 974: Liver Damage and Regeneration \\ Düsseldorf, Germany. 15-16 November 2013
}

Bile plays an essential role in the nutrient uptake of the human body. It consists mostly of amphipathic bile salts, phospholipids and cholesterol in mixed micelles. The bile solubilizes lipophilic nutrients, such as lipids and fat-soluble vitamins, and facilitates their uptake. The formation of bile depends on the activity of various ATP-binding cassette $(\mathrm{ABC})$ transporters localized in the apical membrane of hepatocytes. The main components of bile, phosphatidylcholine, cholesterol and bile salts, are transported by multidrug resistance protein 3 (MDR3, ABCB4), ABCG5/G8 and the bile salt export pump (BSEP, ABCB11), respectively. BSEP, as the transporter of the main solute in bile, is considered to be the primary driving force of bile formation.

BSEP belongs to the family of $\mathrm{ABC}$ transporters, which constitute one of the largest protein families. They are primary active transporters with a common functional unit: two nucleotide-binding domains and two transmembrane domains. The nucleotide-binding domains fuel the transport by hydrolyzing ATP, while the transmembrane domains provide the translocation pathway over the membrane and are thought to be responsible for substrate recognition. Eukaryotic $\mathrm{ABC}$ transporters are usually encoded by one gene as in the case of BSEP (fullsize transporters) or by two genes coding for one nucleotide-binding domain and one transmembrane domain each. In the latter case the transporter is called a half-size transporter and the two polypeptides homo- or heterodimerize to form a functional unit. An example for such a half-size transporter is ABCG5/G8. Mutations in ABC transporters can lead to severe diseases. For example an impairment of targeting or activity in BSEP leads to the accumulation of bile salts in the hepatocytes. Bile salts, in addition to their detergent function, can furthermore act

\footnotetext{
* Correspondence: lutz.schmitt@uni-duesseldorf.de

Institute of Biochemistry, Heinrich Heine University, 40225 Düsseldorf,
} Germany

as signaling molecules and thereby cause different forms of cholestasis, such as progressive familial intrahepatic cholestasis type 2 (PFIC2) or benign recurrent intrahepatic cholestasis type 2 (BRIC2).

An additional influence that can affect the development of diseases is the post-translational regulation of $\mathrm{ABC}$ transporter functionality. The regulation can occur directly in the form of chemical modifications or can be mediated for example by protein-protein interactions. For several $A B C$ transporters of the apical hepatocyte membrane an influence of protein-protein interactions on targeting, turnover or activity could be shown.

MRP2 for example interacts with NHERF-1, a scaffold protein that is responsible for linking its interacting partners to the cytoskeleton. It has furthermore been reported that the interaction of MRP2 with NHERF-1 influences the apical membrane expression of MRP2. For example, NHERF-1 knock-out mice show reduced abundance of MRP2 in the membrane [1].

For BSEP two interaction partners are known to date. One of them is the AP2 adaptor related protein complex, which is involved in internalization of BSEP [2].

To study $\mathrm{ABC}$ transporters in their isolated form a heterologous overexpression system is required to obtain sufficient amounts of protein. Initially, toxicity of the BSEP cDNA for Escherichia coli was an obstacle. Therefore a Saccharomyces cerevisiae based cloning technique has been developed, which is independent of $E$. coli [3]. Subsequently, with the optimized cloning procedure an overexpression of BSEP could be established in the methylotrophic yeast Pichia pastoris. With the help of a GFP-fusion protein BSEP could be traced to the P. pastoris plasma membrane. Additionally, sucrose density centrifugation experiments conmed the correct localization of BSEP. A subsequent detergent screen led to the identification of detergents suitable for BSEP solubilization. The transporter appears to be in a detergent-resistant environment as only the lipid-like, 
zwitter-ionic detergents of the Fos-choline and Cyclofos series, comparatively "harsh" detergents, could efficiently extract BSEP. Finally, a purification protocol was established to obtain BSEP in a detergent-solubilized form. With a dual-affinity tag tandem affinity purification could be employed to obtain the $\mathrm{ABC}$ transporter with approximately $75 \%$ purity [4].

In summary, the optimized cloning strategy for BSEP cDNA in S. cerevisiae as well as the efficient expression and purification protocols enable us to investigate the interaction of BSEP with other proteins in vitro.

\section{Acknowledgments}

We thank Dr. Philipp Ellinger and our collaboration partners Prof. Dr. Ralf Kubitz and Dr. Jan Stindt. Special thanks go to Dr. Diana Kleinschrodt and Iris Fey for stimulating discussions and support. This work is supported by the German Research Foundation (CRC 974).

Published: 19 June 2014

\section{References}

1. Li M, Wang W, Soroka CJ, Mennone A, Harry K, Weinman EJ, Boyer JL: NHERF-1 binds to Mrp2 and regulates hepatic Mrp2 expression and function. J Biol Chem 2010, 285:19299-19307.

2. Hayashi H, Inamura K, Aida K, Naoi S, Horikawa R, Nagasaka H, Takatani T, Fukushima T, Hattori A, Yabuki T, Horii I, Sugiyama Y: AP2 adaptor complex mediates bile salt export pump internalization and modulates its hepatocanalicular expression and transport function. Hepatology 2012, 55:1889-1900

3. Stindt J, Ellinger $P$, Stross $C$, Keitel V, Häussinger D, Smits SHJ, Kubitz R, Schmitt $L$ : Heterologous overexpression and mutagenesis of the human bile salt export pump (ABCB11) using DREAM (Directed REcombinationAssisted Mutagenesis). PLoS One 2011, 6:e20562.

4. Ellinger $P$, Kluth $M$, Stindt J, Smits SHJ, Schmitt L: Detergent screening and purification of the human liver $A B C$ transporters BSEP (ABCB11) and MDR3 (ABCB4) expressed in the yeast Pichia pastoris. PLoS One 2013, 8: e60620.

doi:10.1186/2047-783X-19-S1-S20

Cite this article as: Przybylla and Schmitt: Posttranslational regulation of the bile salt export pump. European Journal of Medical Research 2014 19(Suppl 1):S20.

\section{Submit your next manuscript to BioMed Central} and take full advantage of:

- Convenient online submission

- Thorough peer review

- No space constraints or color figure charges

- Immediate publication on acceptance

- Inclusion in PubMed, CAS, Scopus and Google Scholar

- Research which is freely available for redistribution

Submit your manuscript at www.biomedcentral.com/submit
C Biomed Central 